\title{
An Empirical Study on the Impact of Knowledge Intensive Business Service on Technology Innovation of Equipment Manufacturing Industry
}

\author{
Xiaonan Fan $^{1 *}$, Jialun $\mathrm{Li}^{1}$ \\ ${ }^{1}$ School Of Management, Dalian Polytechnic University, Dalian, Liaoning, 116034, China
}

\begin{abstract}
The knowledge intensive business service has obvious technological innovation effects. It can promote the technological innovation of the equipment manufacturing industry and enhance the innovation capability of the equipment manufacturing industry through the integration and diffusion of knowledge, technology, human resources and other resources. Taking the equipment manufacturing industry and knowledge intensive business service in Liaoning Province of China as the research objects, this paper analyzes the mechanism of knowledge intensive business service in promoting equipment manufacturing innovation, and constructs a model of the impact of knowledge intensive business service on the innovation of equipment manufacturing industry.
\end{abstract}

\section{Introduction}

"Made in China 2025" pointed out that in the field of traditional manufacturing, it is necessary to actively implement industrial strong foundation projects, promote the transformation of traditional industries from factordriven to innovation-driven, low-and mid-end production to high-end manufacturing, and give priority to the development of advanced equipment manufacturing to promote the new generation and the integration of information technology and equipment manufacturing.

With the knowledge economy era, Knowledge Intensive Business Service(KIBS), as the main part of the knowledge information services subsystem, providing knowledge-based intermediate goods and services to the community, which including information transmission, software and information technology service industry, financial industry, leasing and business service industry, scientific research and technical service industry have continuously enhanced the driving role of the national economy and regional industrial structure upgrading. Then, will the Knowledge Intensive Business Service affect the technological innovation of the equipment manufacturing industry? How to promote the technological innovation of the equipment manufacturing industry by promoting the development of Knowledge Intensive Business Service?

This paper studies the impact of knowledge intensive business service in Liaoning Province of China on equipment manufacturing innovation not only has important guiding significance for the economic development of Liaoning Province, but also has a certain guiding role for the national equipment manufacturing industry about how to transform from resource-driven to innovation-driven and service-driven.

\section{Empirical test}

\subsection{Model setting}

\subsubsection{Basic model}

$$
Y=A L^{\alpha} K^{\beta} e^{\sum \gamma_{i} X_{i}} e^{\varepsilon}
$$

Take the logarithm to get

$$
\ln Y=\ln A+\alpha \ln L+\beta \ln K+\sum \gamma_{i} X_{i}+\varepsilon
$$

Among them, $Y$ represents the technological innovation output of the equipment manufacturing industry, $A$ is a constant term, $L$ represents the R\&D labor input, $K$ represents the R\&D capital input, $\alpha, \beta$ and $\gamma_{i}$ are parameters to be estimated, and $\varepsilon$ is a random error term.

\footnotetext{
*Corresponding author's e-mail: fanxn@dlpu.edu.cn
} 


\subsubsection{Model extension based on direct impact mechanism}

Therefore, it should be introduced to indicate other than the equipment manufacturing industry. The variable of R\&D investment of institutions and enterprises with scientific research activities; considering the interactive

$$
\sum \gamma_{i} X_{i}=\gamma_{1} \ln O I E+\gamma_{2} \ln
$$

Among them, represents the R\&D investment of other institutions and enterprises with scientific research activities except the equipment manufacturing industry,

$\ln Y=\ln A+\alpha \ln L+\beta \ln K+\gamma_{1} \ln O I E$ (4)

\subsubsection{Indirect influence mechanism based extension mechanism}

In order to test the impact of the functional mechanism of human capital, the interaction term $\ln O I E \times \ln R S$

$$
\ln Y=\ln A+\alpha \ln L+\beta \ln K+\gamma_{1} \ln O I E+\gamma_{2} \ln
$$

In order to test the indirect impact of innovation as an intermediary mechanism, the interaction term $\ln O I E \times \ln T C$ of the $\mathrm{R} \& \mathrm{D}$ input variable of institutions and enterprises with scientific research activities other than the equipment manufacturing

$$
\ln Y=\ln A+\alpha \ln L+\beta \ln K+\gamma_{1} \ln O I E+\gamma_{2} \ln T C+\gamma_{3} \ln O I E \times \ln T C+\varepsilon
$$

\subsection{Variable description and data source}

Date from "The China Statistical Yearbook on Science And Technology","China Science and Technology Statistical Yearbook","China Science and Technology Statistical Yearbook" and "The statistical yearbook of China's tertiary industry".

\section{Empirical results and conclusions}

\subsection{Empirical research}

The coefficient of $\operatorname{lnKIBS} \times \operatorname{lnOIE}$ is 0.093 , which is the same as the expected sign, and passed the significance test at the 5\% level. In addition to the equipment manufacturing industry, other enterprises and institutions' R\&D investment and knowledge intensive business service have a positive impact, and the test results are significant. The lnKIBS coefficient is influence of knowledge intensive business service with other institutions and enterprises with scientific research activities, the interactive terms of the above two variables should also be introduced. The specific model is: service, and is an interactive item.

In summary, the basic model is as follows:

$+\gamma_{2} \ln K I B S+\gamma_{3} \ln O I E \times \ln K I B S+\varepsilon$

between the R\&D input variables of other institutions with scientific research activities (except equipment manufacturing) and enterprises and the employment number of public employment service agencies is used as the replacement explanatory variable of the basic model:

industry and the technology contract transaction amount variable in the technology market is used as the replacement explanatory variable of the basic model to construct the model as follows :

positive, the lnoie coefficient is negative, and the $\operatorname{lnKIBS} \times \ln \mathrm{OIE}$ coefficient is positive.

The $\ln R S \times \ln$ OIE coefficient is 0.068 , which is the same as expected. It has passed the significance test at $5 \%$ level, which shows that knowledge intensive business service promotes the spillover effect of equipment manufacturing industry in Liaoning Province to absorb R\&D investment of other enterprises and institutions with scientific research activities under the function of human capital service mechanism, and indirectly improves the innovation ability of equipment manufacturing industry.

In the regression results, the coefficient of $\ln \mathrm{TC} \times \ln$ OIE is 0.096 , which is the same as the expected sign. It has passed the significance test at 5\% level, which shows that knowledge intensive business service promotes the spillover effect of equipment manufacturing industry in Liaoning Province to absorb R\&D investment of other enterprises and institutions under the role of innovation intermediary mechanism, and indirectly improves the innovation ability of equipment manufacturing industry.

Table 1. Empirical Results.

\begin{tabular}{cccc} 
Explanatory & \multicolumn{3}{c}{ Explained variable $\ln \mathrm{Y}$} \\
\cline { 2 - 3 } variables & The basic model & Human capital & Innovating intermediary \\
& & service mechanism & mechanism \\
\cline { 2 - 4 } & &
\end{tabular}




\begin{tabular}{|c|c|c|c|c|c|c|}
\hline & coefficient & Sig & coefficient & Sig & coefficient & Sig \\
\hline $\ln \mathrm{A}$ & -0.987 & 0.673 & 6.233 & 0.119 & 4.778 & 0.285 \\
\hline $\ln K$ & $0.693 * * *$ & 0.000 & $0.671 * * *$ & 0.000 & $0.774 * * *$ & 0.000 \\
\hline $\ln \mathrm{L}$ & $0.054 * *$ & 0.037 & $0.185^{* *}$ & 0.018 & $0.124 * *$ & 0.032 \\
\hline $\operatorname{lnOIE}$ & $-0.334 * *$ & 0.036 & $-0.020 * *$ & 0.041 & $-0.418 * *$ & 0.027 \\
\hline $\operatorname{lnKIBS}$ & $0.342 * * *$ & 0.008 & & & & \\
\hline $\ln K I B S \times \ln O$ & $0.093 * *$ & 0.023 & & & & \\
\hline \multicolumn{7}{|l|}{ IE } \\
\hline $\ln R S$ & & & 0.002 & 0.517 & & \\
\hline $\operatorname{lnRS} \times \ln \mathrm{OIE}$ & & & $0.068 * *$ & 0.028 & & \\
\hline $\ln \mathrm{TC}$ & & & & & $0.289 * *$ & 0.013 \\
\hline $\operatorname{lnTC} \times \ln \mathrm{OIE}$ & & & & & $0.096 * *$ & 0.015 \\
\hline Adjusted $\mathrm{R}^{2}$ & \multicolumn{2}{|l|}{0.812} & \multicolumn{2}{|c|}{0.748} & \multicolumn{2}{|c|}{0.793} \\
\hline
\end{tabular}

Note: $* * *$ and $* *$ indicate significant at the $1 \%$ and $5 \%$ levels, respectively.

\subsection{The conclusion}

Knowledge intensive business service has a direct impact on the innovation of equipment manufacturing industry, and the impact is relatively indirect. It is consistent with the analysis results in Chapter 2 that the structure of knowledge intensive business service in Liaoning Province is still dominated by standardized service mode. Under the standardized production mode, the service process of knowledge intensive business service is closer to the innovation mode of traditional manufacturing industry.

The innovation output of equipment manufacturing industry is still more dependent on the input of $R \& D$ capital, and the elasticity of capital input is greater than that of human resource input. In the process of innovation, the role of $R \& D$ personnel is relatively limited, and the contribution to innovation is small, and there is still a lack of innovative talents.

\section{$4 \quad$ Policy analysis on promoting innovation in equipment manufacturing industry}

\subsection{Actively develop knowledge intensive business service}

Through the previous analysis, we can see that there is a close relationship between knowledge intensive business service and equipment manufacturing industry. knowledge intensive business service not only has a direct impact on the innovation of equipment manufacturing industry, but also indirectly promotes the innovation of equipment manufacturing industry in Liaoning Province under the role of human capital service mechanism and innovation intermediary mechanism. At present, Liaoning Province is in the bottleneck stage of economic development, and the development of equipment manufacturing industry is stagnant or even declined. Actively developing knowledge intensive business service plays an important role in promoting the innovation and development of equipment manufacturing industry.

\subsection{Industrial level}

In order to strengthen the interaction between equipment manufacturing industry and knowledge intensive business service, the government should pay attention to the development planning of knowledge intensive business service and equipment manufacturing industry in Liaoning Province. The government focuses on the construction of knowledge intensive business service cluster. Through industrial agglomeration, knowledge, technology, talent and other production factors are highly gathered to accelerate the development of the whole industry, promote the penetration of knowledge intensive business service into all aspects of equipment manufacturing industry in Liaoning Province, and increase the interaction between of them.

\subsection{Actively cultivate innovative talents in equipment manufacturing industry}

From the empirical results, we can see that the innovation output of equipment manufacturing industry is still more dependent on $\mathrm{R} \& \mathrm{D}$ capital input, the elasticity of capital input is greater than that of human 
input, the innovation mode is still extensive, the role of R\&D personnel in the innovation process is relatively limited, the contribution to innovation is small, and there is still a lack of innovative talents. Therefore, in terms of the equipment manufacturing industry itself, to improve the innovation ability, we should pay attention to the cultivation of innovative talents, and fundamentally, we should start from education to cultivate students' innovative thinking and innovative ability.

\section{References}

1. Miles, I., Kastrinos, N., (1998) Knowledgeintensive business services: users, carriers and sources of innovation. Second National Knowledge Infrastructure Setp, 44: 100-128.

2. Amara, N., Landry, R., Traore, N., (2008) Managing the protection of innovations in knowledge-

intensive business services. Research Policy, 37: 1530-1547.

3. Muller, E., Zenker A., (2001) Business services as actors of knowledge transformation: the role of KIBS in regional and national innovation systems. Research Policy: 30.

4. Ciriaci, D., Montresor, S., Palma, D., (2015) Do KIBS make manufacturing more innovative? An empirical investigation of four European countries. Technological Forecasting \& Social Change, 95: 135-151.

5. Antonelli, C., (1998) Localized technological change, new information technology and the knowledge-based economy: The European evidence. Journal of Evolutionary Economics, 8: 177-198.

6. Doloreux, D., Shearmur, R., (2012) How much does KIBS contribute to R\&D activities of manufacturing firms?. Economia Politica, 29: 319-341. 